\title{
RANCANG BANGUN SISTEM MONITORING DETAK JANTUNG MENGGUNAKAN ELEKTROKARDIOGRAF BERBASIS BLUETOOTH DAN LABVIEW
}

\author{
Syah Alam ${ }^{1}$, Sri Hartanto ${ }^{2}$, Ikbal Pratama ${ }^{3}$ \\ ${ }^{1}$ Jurusan Teknik Elektro, Universitas Trisakti \\ ${ }^{2}$ Program Studi Teknik Elektro, Universitas Krisnadwipayana \\ ${ }^{3}$ Program Studi Teknik Elektro, Sekolah Tinggi Teknologi Indonesia \\ Email: 1'syah.alam@trisakti.ac.id, ${ }^{2}$ sri.hartanto@gmail.com, ${ }^{3}$ ikbalpratama54@ gmail.com
}

\begin{abstract}
Abstrak
Abstrak-- Elektrokardiograf (EKG) adalah alat yang digunakan untuk mendeteksi detak jantung pada manusia yang biasa digunakan dirumah sakit khususnya pada ruang ICU. Pada umumnya alat EKG dikendalikan secara manual menggunakan medium kabel sehingga memiliki keterbatasan jarak dan akses untuk melakukan monitoring. Penelitian ini mengusulkan rancang bangun prototype alat monitoring detak jantung pada manusia dengan berbasis arduino dan labview yang dikomunikasikan menggunakan Bluetooth agar dapat diakases secara efektif menggunakan wireless. Perancangan dilakukan menggunakan sensor elektroda yang dihubungkan dengan penguat awal, band pass filter, penguat akhir, rangkaian clamper dan arduino uno yang dihubungkan dengan modul bluetooth serial HC-05 dan dapat dimonitor menggunakan labview menggunakan Personal Computer (PC). Dari hasil pengujian dan pengukuran, diperoleh jarak maksimal monitoring adalah 5 meter dengan tanpa halangan serta tingkat keakuratan detak jantung $96.1 \%$ jika dibandingkan dengan detak jantung yang di deteksi dari nadi manusia. Hasil ini menunjukkan bahwa prototype yang diusulkan dapat bekerja dengan baik dan memenuhi syarat untuk dapat diaplikasikan pada sistem pendeketsi detak jantung manusia menggunakan elektrokardiograf.
\end{abstract}

Kata Kunci: elektrokardiograf, arduino uno, bluetooth, labview, detak jantung

\begin{abstract}
Electrocardiograph (ECG) is a device used to detect heartbeat in humans commonly used in hospitals, especially in the ICU. In general, ECG tools are controlled manually using wireline so that they have limited distance and access to monitoring. This study proposes the design of a heart rate monitoring device prototype with Arduino-based and Labview which is communicated using Bluetooth so that it can be accessed effectively using wireless. The design was carried out using an electrode sensor connected to the initial amplifier, band pass filter, final amplifier, clamper circuit and Arduino Uno connected to the HC-05 serial Bluetooth module and can be monitored using Labview using a Personal Computer (PC). Fromthe results of testing and measurement, the maximum distance of monitoring is 5 meters withnoobstacle and the accuracy of heart rate is $96.1 \%$ when compared to the heart rate detected by human pulse. These results indicate that the proposed prototype can work well and meet the requirements to be applied to the human heart rate deterioration system using an electrocardiograph.
\end{abstract}

Keywords: electrocardiograph, arduino uno, Bluetooth, labview, heart rate 


\section{PENDAHULUAN}

Perkembangan teknologi di dunia kedokteran semakin maju dan pesat salah satunya teknologi bidang biomedis. USG, CT-SCAN, EKG, EMG adalah beberapa perkembangan teknologi yang sudah biasa digunakan di rumah sakit (Nastiti, A. K., Purwanti, E., \& Supardi, A., 2013).

Salah satu peralatan elektronika medis yang mendasar dan digunakan oleh semua dokter adalah Elektokardiograf (EKG). Alat EKG ini berfungsi untuk mendeteksi detak jantung dari manusia dengan menggunakan sinyal analog yang akan muncul di layar monitor, umumnya alat ini tersedia di ruang ICU dan digunakan untuk pasien yang sedang dalam kondisi rileks. Selain itu, alat ini hanya dapat dimonitor secara langsung oleh perawat ataupun dokter. (Mozaffarian, D., Benjamin, E. J., Go, A. S., Arnett, D. K., Blaha, M. J., Cushman, M., Howard, V. J., 2016).

Untuk itu diperlukan sebuah sistem monitoring jarak jauh untuk dapat mengakses hasil pengecekan jantung tanpa harus masuk ke kamar pasien. Hal ini juga untuk meningkatkan kenyamanan pasien dan juga untuk membantu dokter dan perawat dalam memberikan pelayanan yang maksimal dalam mengontrol kondisi dari pasien (Permana, 2015).

Penelitian ini sebelumnya sudah pernah dilakukan oleh (Iskandar, 2015) yaitu merancang alat EKG portable namun masih belum dapai dikendalikan dengan menggunakan wireless. Berdasarkan latar belakang masalah diatas, pada penelitian ini dilakukan perancangan alat monitoring detak jantung manusia berbasis arudino uni dengan menggunakan sistem komunikasi Bluetooth . Tujuan dari penelitian ini adalah untuk merancang alat rekam jantung Elektrokardiografi (EKG) yang portabel, praktis dan nirkabel dengan memanfaatkan komunikasi Bluetooth dan Labview sebagai visualisasi rekaman dari rangkaian pengkondisi sinyal EKG.

\section{METODE}

Pada dasarnya sebelum merancang suatu alat secara sistematik dibutuhkan suatu blok diagram sistem. Gambar 1 di bawah ini menunjukkan blok diagram dari Implementasi Rancang Bangun Monitoring Kesehatan Jantung menggunakan Analisa Elektrokardiografi (EKG) berbasis Sistem Komunikasi Bluetooth [9].

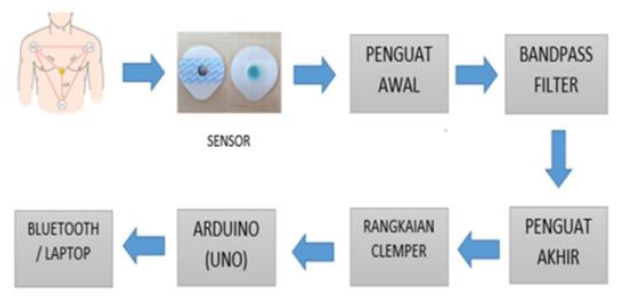

Gambar 1. Blok Diagram Sistem

Gambar 1 adalah blok diagram sistem perancangan dari alat yang diusulkan . Pada tahapan awal sensor elektroda yang ditempatkan ditubuh bagian dada pasien akan mendeteksi perubahan denyut jantung pasien. Sinyal hasil deteksi dari sensor elektroda diteruskan ke penguat awal untuk dikuatkan kembali. Selanjutnya sinyal yang telah dikuatkan lalu di filter menggunakan band pass filter yang merupakan gabungan antara low pass dan high pass filter. Fungsi dari filyer ini adalah untuk mengurangi noise yang masuk bersama sinyal yang dideteksi oleh sensor katoda. Sinyal yang telah difilter selanjutnya dikuatkan kembali agar dapat terbaca oleh mikrokotroller. Sebelum masuk ke dalam mikrokontroller, sinyal keluaran lalu di digeser nilainya agar menjadi positif dengan menggunakan rangkaian clamper. Hal ini dilakukan agar sinyal yang di hasilkan dapat di digitalisasi dan dapat di proses menggunakan mikrokontroller. Setelah sinyal bernilai positif maka tahapan selanjutnya adalah melakukan proses pengiriman sinyal dengan menggunakan bluetooth yang nanti akan diterima dan dapat dimonitor oleh perawat ataupun dokter menggunakan Personal Computer .

Pada penelitian ini digunakan jenis mikrokontroller arduino uno (Arduino, 2015). Untuk jenis penguat yang digunakan adalah AD620 hal ini dikarenakan mempunyai slewrate yang lebih tinggi, gain hingga 10.000 kali (Datasheet amplifiers AD 620 series), Bandwidth yang lebar dan CMRR yang besar. Untuk penguat op-amp digunakan jenis OP07 (Datasheet operational amplifier OP0 series), karena cocok digunakan untuk perancangan alat EKG ini yang mana membutuhkan penguatan disetiap tahap dan rentan terhadap gangguan atau noise.

\subsection{Perancangan Penguat Awal}

Pada perancangan rangakaian penguat awal dalam perangkat monitoring EKG tahap pertama ini akan digunakan sebuah IC penguat instrumentasi AD620 dengan besar penguatan sebsesar 127 kali penguatan. 


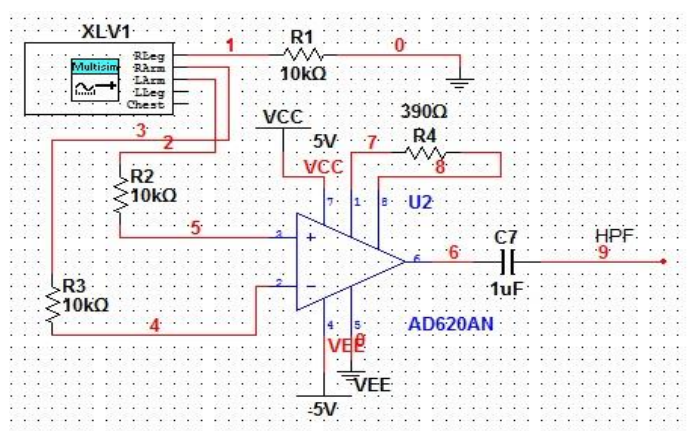

Gambar 2. Rangkaian Penguat Awal

Gambar 2 menunjukkan rangkaian penguat tahap pertama dari sinyal EKG Nilai penguatan dari penguat awal dapat diatur untuk dengan mengontrol nilai resistansi pada $R_{4}$. Pada penelitian ini, nilai penguatan awal pada sinyal EKG ini adalah 127 kali hal ini dikarenakan amplitudo sinyal EKG yang dideteksi oleh sensore elektroda yang dipasang pada tubuh pasien hanya mempunyai nilai amplitudo sebesar 3 mili Volt, Untuk itu akan dilakukan penguatan secara bertahap dan bertingkat agar mendapatkan amplitudo sinyal EKG yang bernilai di atas 1 Volt sehingga sinyak keluaran dapat diolah oleh ADC mikrokontroler. Untuk mendapatkan nilai resistansi $R_{4}$ yang sesuai dengan nilai penguatan 127 kali dapat menggunakan persamaan (1):

$$
\begin{aligned}
& \mathrm{R}_{4}=\frac{49,5 \mathrm{k} \Omega}{\mathrm{G}-1} \\
& \mathrm{R}_{4}=\frac{49,5 \mathrm{k} \Omega}{127-1} \\
& \mathrm{R}_{4}=390 \Omega
\end{aligned}
$$

Untuk menghitung dan memverikasi nilai penguatan awal pada sinyal awal EKG dapat menggunakan persamaan (2) :

$$
\begin{aligned}
& \mathrm{G}_{1}=\frac{49,5 \mathrm{k} \Omega}{\mathrm{R} 4}+1 \\
& \mathrm{G}_{1}=\frac{49,5 \mathrm{k} \Omega}{390 \Omega}+1 \\
& \mathrm{G}_{1}=127
\end{aligned}
$$

Dengan menggunakan persamaan (1) dan persamaan(2) diatas, didapatkan hasil penguatan awal sebesar 127 kali penguatan dengan nilai resistansi $\mathrm{R}_{4}$ sebesar $390 \Omega$.

\subsection{Perancangan Penguat Akhir}

Pada perancangan rangkaian penguat akhir dalam perangkat monitoring EKG ini digunakan sebuah IC penguat op-amp OP07 dengan besar penguatan yang diatur sebesar 11 kali seperti yang ditunjukkan pada gambar 3.

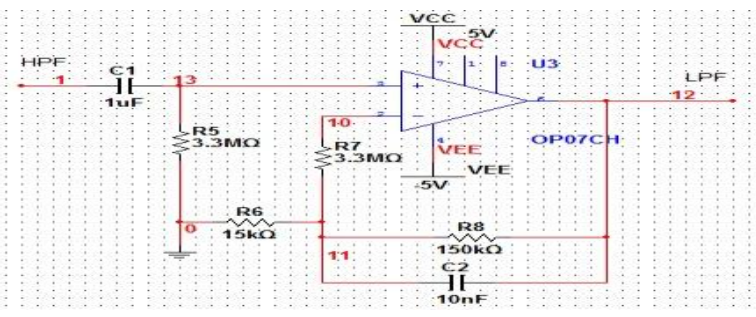

Gambar 3. Penguatan Akhir

Nilai dari penguatan akhir dapat diperoleh menggunakan persamaan (3):

$$
\begin{aligned}
& \mathrm{G}_{2}=\left(1+\frac{R 8}{R 6}\right) \\
& \mathrm{G}_{2}=\left(1+\frac{150 \mathrm{~K}}{15 k}\right) \\
& \mathrm{G}_{2}=11
\end{aligned}
$$

Setelah diperoleh penguatan awal dan penguatan akhir yang digunakan pada penelitian ini, maka total penguatan keseluruhan dapat dihitung dengan menggunakan persamaan (4) :

$$
\begin{aligned}
\text { Total Gain }= & \mathrm{G}_{1} \times \mathrm{G}_{2} \\
& =127 \times 11=1397 \mathrm{kali}
\end{aligned}
$$

\subsection{Perancangan Rangkaian Filter}

Frekeunsi yang dibutuhkan untuk sinyal EKG mempunyai rentang bandwidth sekitar $0.03-100$ Hz. Agar alat yang dirancang dapat bekerja pada frekuensi yang diinginkan maka digunakan filter frekuensi. Fungsi dari filter adalah untuk melewatkan frekuensi yang digunakan dan menahan frekuensi yang tidak digunakan. Pada penelitian ini digunakan band pass filter yang merupakan gabungan antara low pass filter dan high pass filter (Khan, 2016) dengan rentang frekuensi kerja 0.03 $100 \mathrm{~Hz}$.

Rangkaian penguat dan filter secara keseluruhan yang dirancang pada alat EKG ini terdiri dari rangkaian penguat bandpass filter yang terdiri dari high pass filter, dan low pas filter seperti yang ditunjukkan pada gambar 4 .

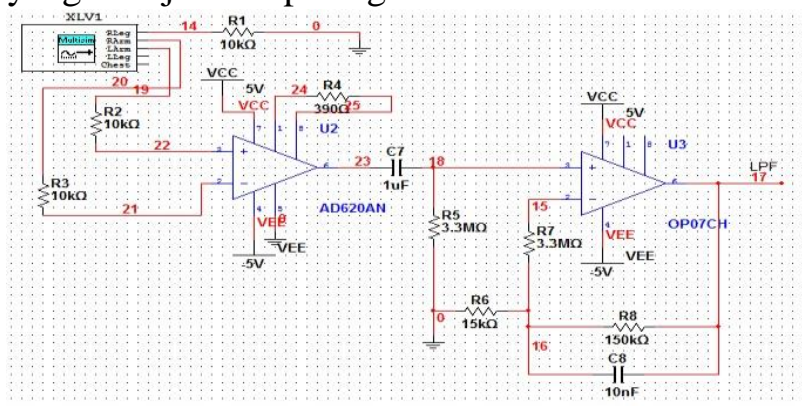

Gambar 4. Rangkaian Penguat dan Filter Keseluruhan 


\subsection{Perancangan Rangkaian Clamper}

Pada tahap akhir karena sinyal data yang dihasilkan dari proses sebelumnya masih memiliki amplitudo yang negatif, maka digunakan rangkaian clamper positif yang berfungsi untuk menggeser nilai tegangan agar berada di atas nol atau positif tanpa mengubah amplitudo dari sinyal data yang didapat. Ini bertujuan agar sinyal data yang didapat tidak terpotong, rangkaian clamper dapat dilihat pada gambar 5 .

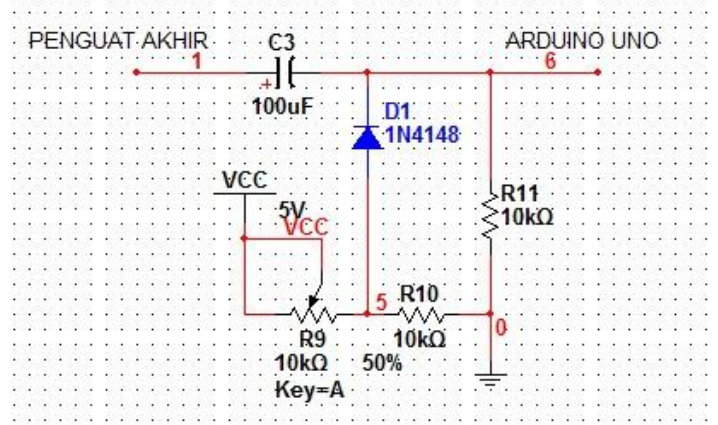

Gambar 5. Rangkaian Clamper

\subsection{Hasil Pengujian Penguat}

Setelah melakukan tahap perancangan rangkaian dan perhitungan berdasarkan teori yang diterapkan pada rangkaian penguat dan filter EKG ini maka, hasil rangkaian harus mempunyai nilai yang sesuai dengan perancangan yang dijelaskan pada perancangan rangkaian penguat dan filter yang sudah ditentukan.

Setelah diperoleh nilai penguatan awal dan akhir serta rentangan frekuensi kerja dari filter yang digunakan maka dilakukan proses pengujian dari rangkaian yang telah dirancang. Hasil pengukuran penguatan awal dan penguatan akhir dari proses perancangan dapat dilihat pada gambar 6 dan gambar 7.

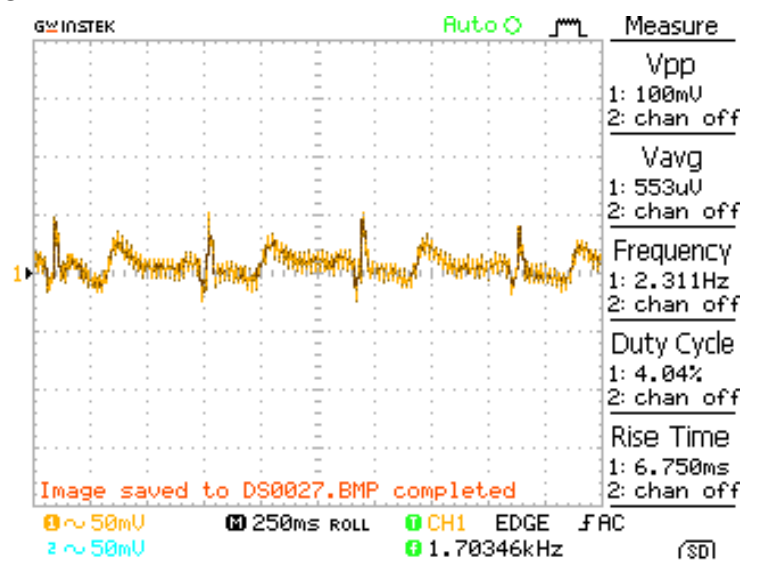

Gambar 6. Hasil Pengukuran Penguatan Awal

Gambar 6 menunjukkan bahwa besar penguatan yang dihasilkan sebanyak 127 kali pada penguatan awal dengan tegangan sebesar $100 \mathrm{mV}$ dengan frekuensi $2.311 \mathrm{~Hz}$ yang belum melewati rangkaian low pass filter dengan cut-off sebesar $106 \mathrm{~Hz}$. Hal ini menunjukkan bahwa rangkaian penguat awal telah sesuai dengan yang dirancang sebelumnya.

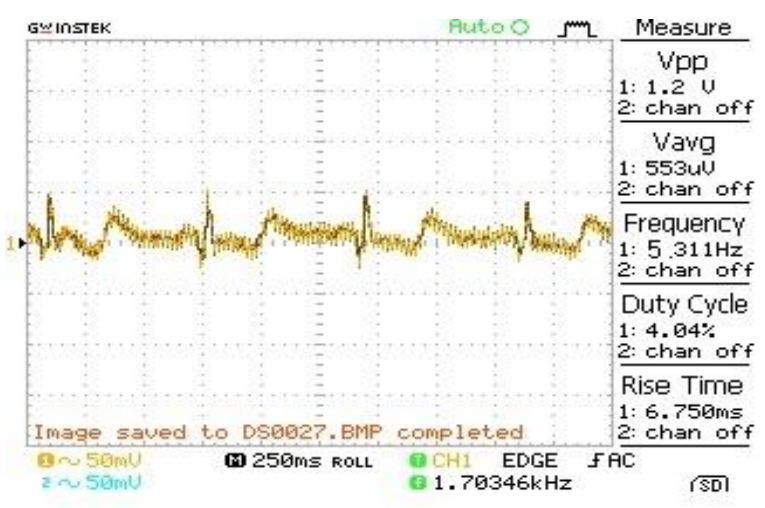

Gambar 7. Hasil Pengukuran Penguatan Akhir

Hasil amplitudo atau V-peak-to-peak penguat akhir pada rangkaian EKG didapatkan sebesar 1.2 Volt dengan frekuensi $5.311 \mathrm{~Hz}$ seperti yang ditampilkan pada gambar 7. Hasil ini telah memenuhi batas minimal yang telah ditetapkan bahwa besar amplitude yang dibutuhkan agar dapat diproses oleh ADC adalah 1 Volt dengan rentang frekuensi kerja EKG $0.03-100 \mathrm{~Hz}$.

\subsection{Perancangan Program Aplikasi Komputer \\ Pada perancangan software ini akan} menjelaskan semua fungsi dari aplikasi yang akan dibuat dan digunakan. Software yang akan digunakan dalam perancangan software adalah LabVIEW 2016.

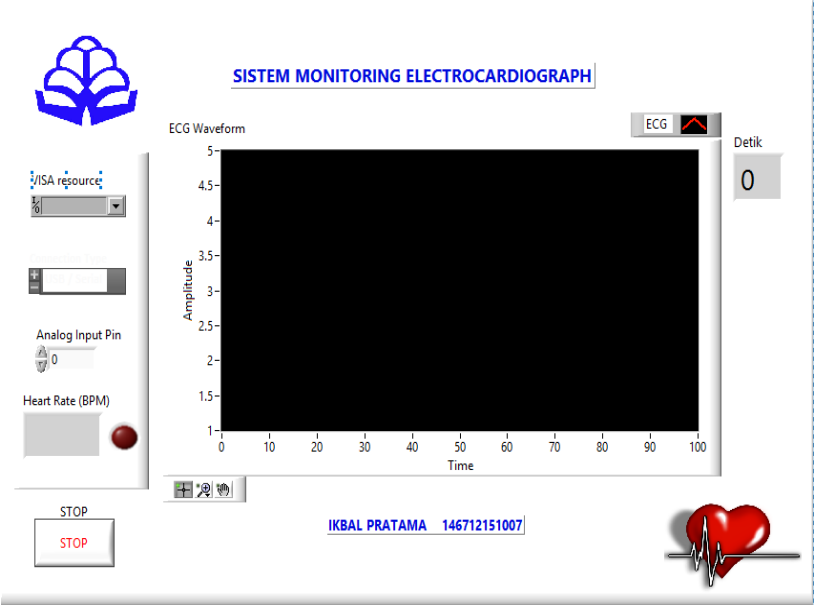

Gambar 8. Tampilan Aplikasi pada PC

Gambar 8 diatas menunjukkan aplikasi tampilan sinyal EKG pada PC yang terdiri dari menu yaitu :

1. VISA resource : Untuk menentukan port yang terhubung antara hardware dan LabVIEW. 
2. Connection Type: Untuk menentukan komunikasi data yang dipakai antara hadware dan LabVIEW.

3. Analog Input Pin : Untuk menentukan pin yang dipakai pada Arduino yang dibubungkan pada alat EKG.

4. Heart Rate (BPM) : Untuk menampilkan hasil perhitungan detak jantung/Heart Beat.

\section{HASIL DAN PEMBAHASAN}

3.1 Rangkaian penguat (awal) instrumentasi dengan penguatan 127 kali.

Pada tahapan ini dilakukan proses pengujian dari penguat awal yang bernilai 127 kali. Pengujian dilakukan dengan mengamati amplitudo dari detak jantung pada 3 orang yang berbeda sebagai objeknya. Hasil pengujian rangkaian penguawa awal dapat dilihat pada Tabel I.

Tabel I. Tabel Hasil pengujian Penguat Instrumentasi 127 kali

\begin{tabular}{|c|c|c|}
\hline Percobaan & Pengukuran & $\begin{array}{c}\text { Amplitudo } \\
\text { Keluaran (Vp-p) }\end{array}$ \\
\hline 1 & Jantung orang ke 1 & $189 \mathrm{mV}$ \\
\hline 2 & Jantung orang ke 2 & $195 \mathrm{mV}$ \\
\hline 3 & Jantung orang ke 3 & $142 \mathrm{mV}$ \\
\hline
\end{tabular}

Dari Tabel I diatas maka diambil sample 3 objek jantung manusia yang memiliki amplitudo (Vp-p) berbeda-beda, dari 3 sample objek jantung tersebut diambil 2 objek yang diukur oleh oscilloscope portable pada gambar 9 dan gambar 10 .

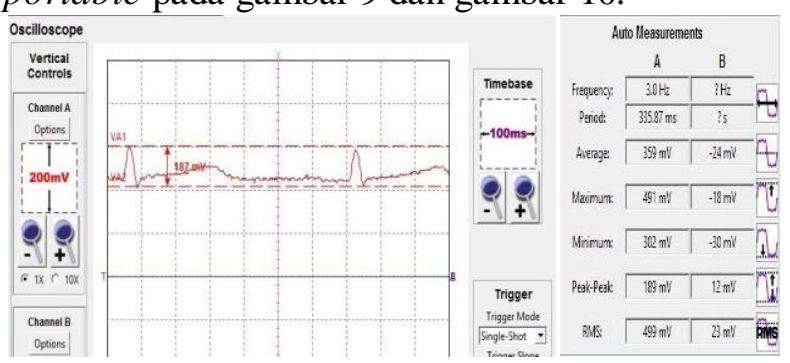

Gambar 9. Hasil penguatan dengan amplitudo $189 \mathrm{mV}$ pada Jantung orang ke-1

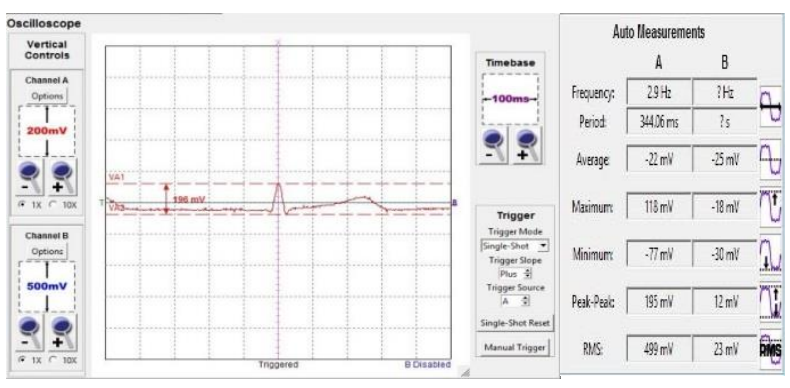

Gambar 10. Hasil penguatan dengan amplitudo $195 \mathrm{mV}$ padaJJantung orang ke-2
Berdasarkan Tabel I diatas dapat dilihat dengan penguatan 127 kali pada tegangan gelombang puncak $\mathrm{R}$ atau tegangan maksimum jantung pada siklus terjadinya detak jantung. Berdasarkan teori parameter gelombang $\mathrm{EKG}$, gelombang $\mathrm{R}$ dalam sinyal EKG mempunyai tegangan 1-3 mV, walau berdasarkan teori parameter sinyal EKG demikian tetapi pada faktanya setiap jantung tubuh manusia tidak memiliki tegangan yang sama karena banyak faktor yang mempengaruhi kondisi tubuh yang normal atau kurang sehat dan lain sebagainya. Dengan menggunakan acuan parameter sinyalEKG yaitu untung gelombang $R$ atau tegangan maksimum saat jantung berdetak dengan penguatan 127 kali seharusnya didapatkan tegangan setiap sample objek jantung sebagai berikut :

a. Pada Objek 1 didapatkan hasil gelombang $R$ atau tegangan maksimum saat jantung berdetak $189 \mathrm{mV} / 127=1.48 \mathrm{mV}$.

b. Pada Objek 2 didapatkan hasil gelombang $\mathrm{R}$ atau tegangan maksimum saat jantung berdetak $195 \mathrm{mV} / 127=1.53 \mathrm{mV}$.

c. Pada Objek 3 didapatkan hasil gelombang $\mathrm{R}$ atau tegangan maksimum saat jantung berdetak $142 \mathrm{mV} / 127=1.1 \mathrm{mV}$.

Berdasarkan perbandingan hasil gelombang $\mathrm{R}$ pada setiap objek dapat disimpulkan bahwa tegangan pada gelombang $\mathrm{R}$ atau tegangan maksimum saat jantung berdetak dapat berubahubah. Ini disebabkan oleh beberapa faktor salah satunya faktor kondisi tubuh yang berbeda beda baik itu kondisi tubuh yang sehat atau kurang sehat dan mempengaruhi tekanan darah pada denyut nadi.

\subsection{Rangkaian bandpass filter.}

Untuk meloloskan frekuensi sinyal EKG perlu digunakan filter yang dapat meredam frekuensi interfensi pada sinyal EKG, untuk kebutuhan monitoring informasi sinyal EKG maka frekuensi yang dibutuhkan harus tepat agar tidak terjadi kehilangan sinyal informasi yang sebenarnya. Digunakan bandpass filter yang terdiri dari dari gabungan lowpass filter dan highpass filter dengan besar frekuensi bandwith $0.05-106 \mathrm{~Hz}$. Hasil pengujian rangkaian EKG tanpa menggunakan filter dan menggunakan bandpass filter dapat dilihat pada gambar 11 (a) dan gambar 11 (b). 


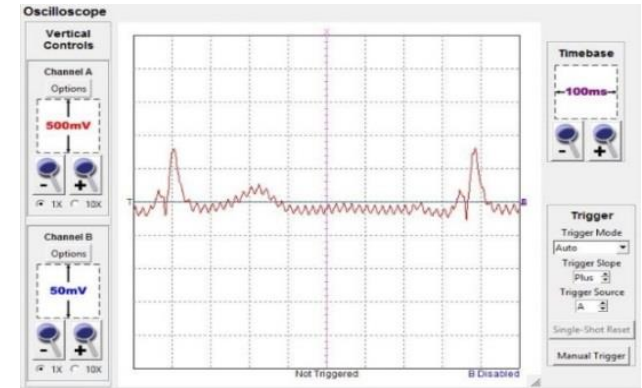

(a)

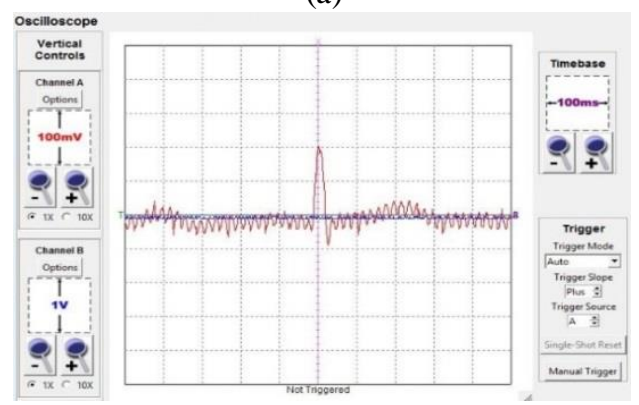

(b)

Gambar 11. Hasil Pengujian Rangkaian EKG ;

(a) Sinyal EKG tanpa filter,

(b) Sinyal EKG dengan bandpass filter

Gambar 11 (a) menunjukkan sinyal keluaran dari rangkaian yang belum di filter sedangkan pada gambar 11 (b) sinyal keluaran telah di filter menggunakan band pass filter. Fungsi dari bandpass filter dalam rangkaian EKG ini adalah untuk mengurangi noise yang terjadi akibat interferensi frekuensi lain yang dapat merubah tampilan karakteristik as li sinyal EKG. Noise atau gangguan pada suatu sistem memang tidak dapat dihilangkan namun noise atau gangguan tersebut dapat dikurangi atau diminimalisir dengan menggunakan filter.

\subsection{Rangkaian penguat (akhir) operasional dengan penguatan 11 kali.}

Rangkaian op-amp dengan penguatan 11 kali ini digunakan untuk menguatkan kembali sinyal EKG yang telah diproses pada rangkaian penguat instrumentasi dan rangkaian filter. Untuk mendapatkan hasil sinyal EKG yang baik maka harus dilakukan penguatan bertingkat atau cascade agar noise atau interferensi dari hasil rekaman langsung sinyal EKG yang masih terbawa pada rangkaian penguat instrumentasi tidak semuanya terbawa karena telah melewati rangkaian filter. Data hasil pengujian rangkaian op-amp ditunjukka pada Tabel II.

Tabel II. Hasil pengujian Op-amp 11 kali

\begin{tabular}{|c|c|c|}
\hline Percobaan & $\begin{array}{c}\text { Amplitudo } \\
\text { Sinyal Input } \\
\text { (Vp-p) }\end{array}$ & $\begin{array}{c}\text { Amplitudo } \\
\text { Sinyal Output } \\
\text { (Vp-p) }\end{array}$ \\
\hline 1 & $189 \mathrm{mV}$ & $2.14 \mathrm{~V}$ \\
\hline 2 & $195 \mathrm{mV}$ & $2.71 \mathrm{~V}$ \\
\hline 3 & $142 \mathrm{mV}$ & $1.09 \mathrm{~V}$ \\
\hline
\end{tabular}

Berdasarkan Tabel II di atas dapat dilihat penguatan op-amp ditetapkan sebesar 11 kali berfungsi untuk menguatkan kembali tegangan dari penguat instrumentasi agar mencapai tegangan 0-5 $\mathrm{V}$, peran penguat op-amp disini juga sebagai filter yang digabungkan dengan resistor dan kapasitor.
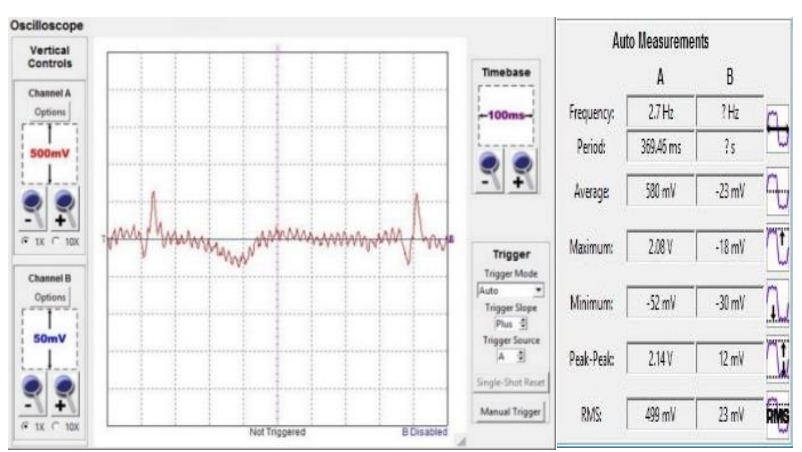

Gambar 12. Hasil Penguatan akhir dengan amplitudo $2.14 \mathrm{~V}$ pada jantung orang ke-1

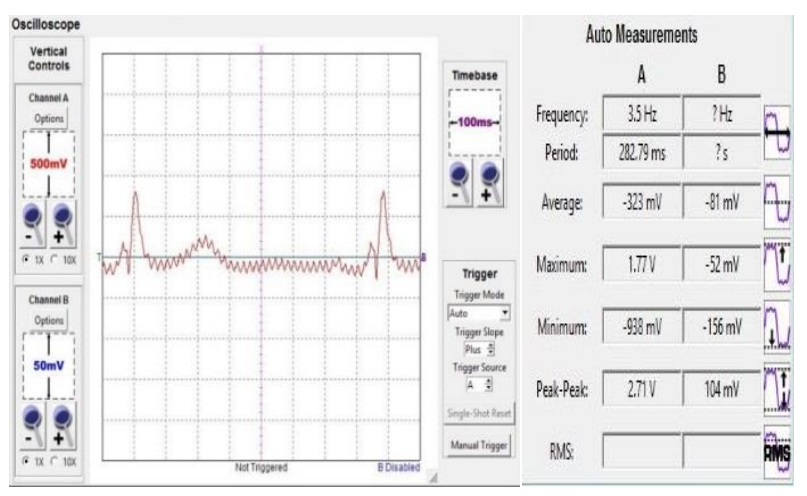

Gambar 13. Hasil Penguatan akhir dengan amplitude 2.71 $\mathrm{V}$ pada jantung orang ke-2

Gambar 12 dan gambar 13 menunjukkan hasil pengujian dari penguatan akhir pada percobaan rangkaian pada jantung orang ke-1 dan ke - 2 sebagai objek penelitian. Pada penguatan $11 \mathrm{kali}$, tegangan peak to peak yang didapatkan adalah $2.14 \mathrm{~V}$ dan $2.71 \mathrm{~V}$, hal ini menunjukkan bahwa tegangan yang dihasilkan dapat diproses oleh mikrokontroller yang membutuhkan tegangan minimum antara 0-5 V. Dari hasil perbandingan penguatan dapat disimpulkan bahwa penguatan bisa berubah-ubah tergantung masukan dari penguat instrumentasi (awal) yang dipengaruhi oleh beberapa faktor yang sama dengan penguat instrumentasi (awal). Namun beda hasil penguatan didapatkan $0-5 \mathrm{~V}$ yang dapat diproses oleh ADC pada mikrokontroler.

\subsection{Rangkaian Clamper}

Rangkaian clamper ini berfugsi untuk menggeser nilai referensi offset sinyal ke atas titik ground sistem, sehingga puncak positif (sinyal di 
atas titik ground) dan puncak negatif (sinyal di bawah titik ground) sinyal tetap berada diantara rentang $0-5$ Volt agar dapat tetap terbaca oleh peranti ADC pada mikrokontroler. Pengujian rangkaian clamper ini dilakukan dengan cara memberi sinyal masukan dari rangkaian op amp yang masih memiliki nilai offset negatif. Setelah itu hasil keluaran dari rangkaian clamper ini akan diamati nilai offset nya. Fungsi dari rangkaian clamper ini adalah menggeser nilai offset batas bawah dan atas dari sinyal keluaran agar tetap berada diatas nilai 0 atau bernilai positif. Pengujian rangkaian clamper dapat dilihat pada gambar 14 (a) dan gambar 14 (b).

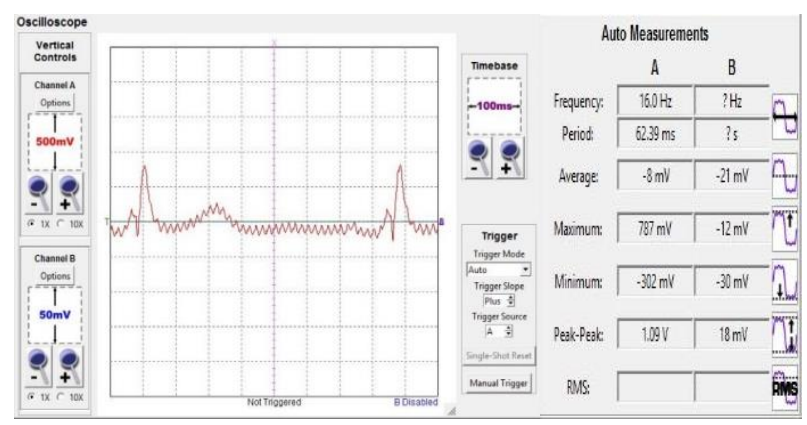

(a)

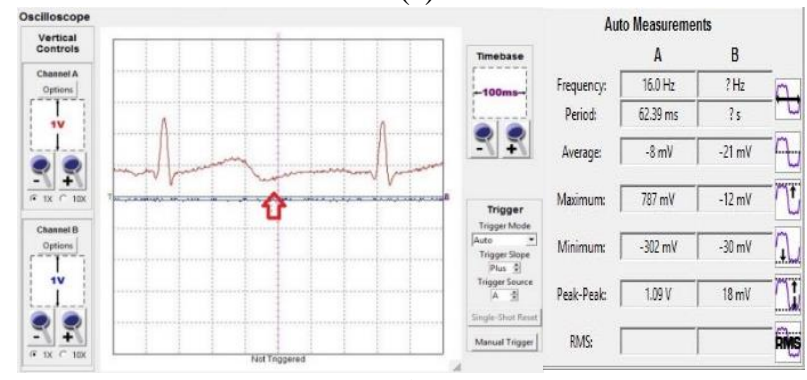

(b)

Gambar 14. Pengujian Rangkaian Clamper;

(a) Sinyal masukan rangkaian op-amp,

(b) Hasil pergeseran dari titik nol pada rangkaian clamper

Gambar 14 (a) menunjukkan sinyal masukan dari rangkaian op-amp dimana sinyal puncak positif dan negatif yang dihasilkan masih berada dibawah titik nol. Setelah menggunakan rangkaian clamper, maka dihasilkan sinyal puncak posotif dan negative yang berada pada rentangan $0-5 \mathrm{~V}$ seperti yang ditunjukkan pada gambar 14 (b).

\subsection{Transmisi Bluetooh}

Pengujian transimisi Bluetooth dilakukan untuk melihat kemampuan jarak maksimal dari modul Bluetooth HC-05 dapat mengirim data rekaman dari rangkaian EKG yang akan diterima oleh PC atau Smartphone sebagai hasil visual rekaman digital EKG.
Tabel III. Hasil Pengujian Transmisi Bluetooth

\begin{tabular}{|c|c|c|c|}
\hline \multirow{2}{*}{ Percobaan } & \multirow{2}{*}{$\begin{array}{c}\text { Jarak } \\
\text { (meter) }\end{array}$} & \multicolumn{2}{|c|}{$\begin{array}{c}\text { Keberhasilan Mengirim Data } \\
\text { Mengunakan koneksi } \\
\text { Bluetooth PC }\end{array}$} \\
\cline { 3 - 4 } & & $\begin{array}{c}\text { Tanpa } \\
\text { Halangan }\end{array}$ & $\begin{array}{c}\text { Dengan } \\
\text { Halangan }\end{array}$ \\
\hline 1 & 1 & Berhasil & Berhasil \\
\hline 2 & 3 & Berhasil & Berhasil \\
\hline 3 & 5 & Berhasil & Gagal \\
\hline
\end{tabular}

Dari tabel pengujian pada Tabel III di atas dapat dilihat jarak kemampuan modul Bluetooth untuk mengirim data sinyal EKG dari alat EKG ke PC , pada keadaan tanpa halangan jarak maksimum yang berhasil dikirim modul Bluetooth dari alat EKG ke PC dan smartphone sekitar 5 meter. Dengan menggunakan modul Bluetooth HC-05 pada perancangan sistem EKG nirkabel ini hanya mampu mengirim data dengan baik kurang lebih sekitar 1 5 meter, yang berarti hanya cukup untuk berkomunikasi antar beda ruangan dengan batasan jarak seperti yang didapatkan pada Tabel 3.

\subsection{Personal Computer / LabVIEW}

Pengujian ini dilakukan untuk melihat respon sinyal EKG yang diproses secara digital agar pembacaan lebih mudah. Didalam program visualisasi ini terdapat filter digital, filter ini berfungsi untuk mendapatkan sinyal EKG yang bersih dan baik tanpa ada interferensi frekuensi lain atau gangguan noise yang dapat merusak sinyal EKG yang telah didigitalisasi oleh ADC.

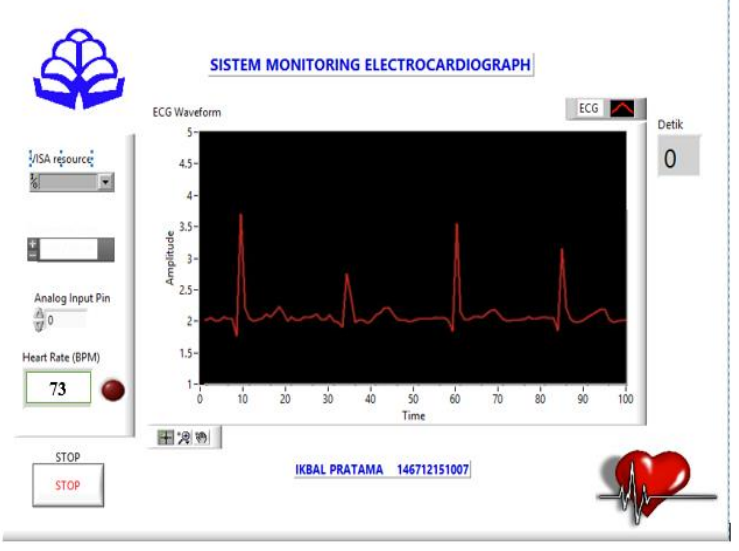

Gambar 15. Hasil rekaman sinyal EKG pada PC

Gambar 15 menunjukkan hasil rekaman sinyal EKG yang telah menggunakan filter, hal ini harus dilakukan untuk mendapatkan rekaman sinyal EKG yang baik serta mengurangi interferensi lain yang masuk pada rangkaian EKG (hardware). Aplikasi monitoring EKG ini juga dapat menghitung detak jantung (heart beat) berdasarkan dari hasil rekaman sinyal EKG yang terbaca, oleh karena itu dibutuhkan hasil rekaman sinyal EKG yang stabil, 
terutama gelombang QRS harus selalu bebas gangguan agar dapat dilakukan proses perhitungan detak jantung dengan menggunakan jarak interval R-R atau puncak gelombang pada jantung dalam satu siklus.

Pengujian skala amplitudo sinyal EKG ini dilakukan untuk melihat respon amplitudo sinyal EKG asli yang telah melalui penguatan pada alat EKG untuk diproses sebagai pengolahan data digital dan mengembalikan skala amplitudo sinyal EKG yang telah di digitalisasi tersebut ke amplitudo asli sinyal EKG jantung. Pengujian ini dilakukan dengan membandingkan hasil sinyal keluaran penguatan total pada rangkaian EKG yang terbaca pada osiloskop dengan hasil keluaran sinyal dari proses ADC dan hasil keluaran sinyal EKG pada aplikasi EKG dengan LabVIEW.

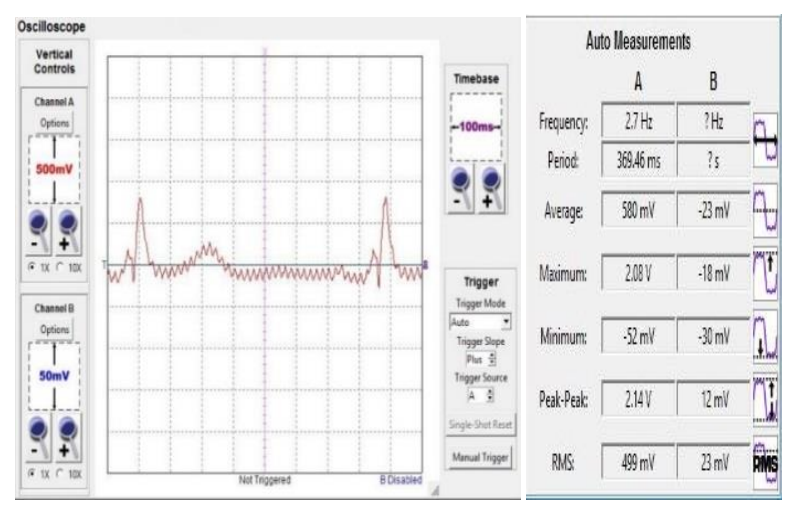

Gambar 16. Hasil Amplitudo siny keluaran Rangkaian EKG

Dari gambar 16 dapat dilihat amplitudo sinyal keluaran rangkaian EKG sebesar $2.14 \mathrm{~V}$, karena hasil tersebut merupakan hasil amplitudo yang telah dikuatkan setelah melalui penguatan bertahap yang mempunyai gain total 1397 kali maka untuk mengetahui nilai amplitudo asli sinyal EKG dapat dihitung $2.14 \mathrm{~V}$ dibagi dengan 1397 kali penguatan yaitu $2.140 \mathrm{mV}: 1397=1.5 \mathrm{mV}$.

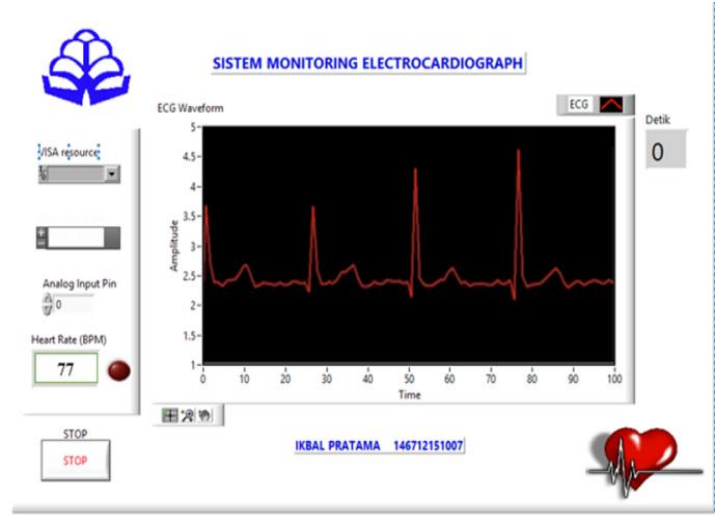

Gambar 17. Hasil Amplitudo Sinyal EKG keluaran ADC
Dari gambar 17 dapat dilihat bahwa pada aplikasi rekaman sinyal EKG mempunyai nilai amplitudo sinyal EKG sebesar $3.5 \mathrm{~V}$, terdapat perbedaan antara sinyal amplitudo dari osiloskop dan hasil pada aplikasi rekaman sinyal EKG. Perbedaan hasil amplitudo sinyal EKG pada osiloskop dan aplikasi rekaman EKG pada PC dikarenakan pembacaan sinyal hasil EKG pada aplikasi sinyal EKG pada PC telah bergeser nilai amplitudonya setelah melalui rangkaian clamper sehingga menghasilkan nilai amplitudo yang besar.

\subsection{Pengujian Detak Jantung}

Pengujian detak jantung atau heart beatpada aplikasi EKG ini dilakukan untuk melihat hasil respon dari perhitungan detak jantung seseorang (BPM/Beat Per Minute) pada aplikasi EKG yang telah dibuat ini berdasarkan hasil rekaman sinyal EKG dan perbandingan dengan data asli jantung. Berikut hasil metode perhitungan detak jantung (BPM) dan tabel hasil perbandingan detak jantung atau heart beat (BPM) dari pengujian yang dilakukan.

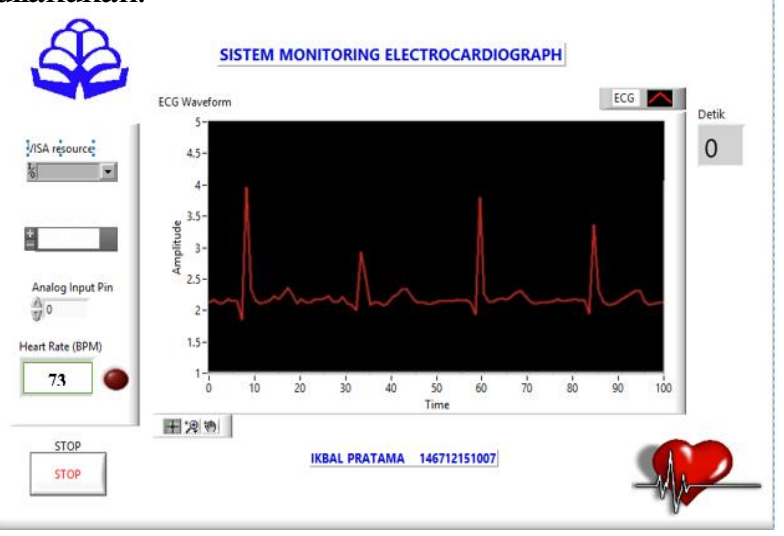

Gambar 18. Proses Perhitungan detak jantung (BPM)

Gambar 18 diatas menunjukkan bahwa proses perhitungan detak jantung (BPM) dilakukan dengan menggunakan perhitungan detak jantung (BPM) berdasarkan rumus metode yang digunakan yaitu, interval R-R dikali 1 menit per 60 detik. Untuk hasil detak jantung (BPM) yang terbaca pada aplikasi mempunyai nilai sebesar 73 BPM. Tabel IV menunjukkan perbandingan hasil pengujian detak jantung menggunakan aplikasi EKG dengan detak jantung asli yang diperoleh dari pengecekan nadi manusia. 
Tabel IV. Hasil Perbandingan Pengujian Detak Jantung

\begin{tabular}{|c|c|c|c|}
\hline \multirow{2}{*}{ Percobaan } & \multicolumn{2}{|c|}{ Hasil Pengujian (BPM) } & \multirow{2}{*}{ Perbedaan } \\
\cline { 2 - 4 } & $\begin{array}{c}\text { Aplikasi } \\
\text { EKG }\end{array}$ & $\begin{array}{c}\text { Perhitungan } \\
\text { Nadi }\end{array}$ & \\
\hline 1 & 73 & 75 & 2 \\
\hline 2 & 77 & 80 & 3 \\
\hline 3 & 54 & 52 & 2 \\
\hline \multicolumn{3}{|c|}{ Rata-rata } \\
\hline
\end{tabular}

Dari data yang ditunjukk pada tabel IV, proses untuk menghitung detak jantung atau heart beat dalam aplikasi EKG ini berdasarkan hasil rekaman sinyal jantung yang tebaca pada grafik, didapatkan hasil detak jantung yang sudah medekati hasil detak jantung asli seseorang dengan rata - rata perbedaan Heart Beat (BPM) yaitu 2 Beat dengan menggunakan cara membandingkan hasil detak jantung yang terbaca pada aplikasi EKG dan menghitung manual atau menghitung langsung detak jantung objek berdasarkan denyut nadi manusia. Kekurangan dalam perhitungan detak jantung pada aplikasi EKG ini adalah perubahan detak jantung 60 detik terkadang kurang stabil, selain faktor kondisi tubuh atau jantung yang tidak tentu atau berubah tiap detiknya faktor gerakan, sensor atau interferensi pada media komunikasijuga dapat mempengaruhi hasil perhitungan detak jantung karena sinyal yang terbaca pada saat perekaman tidak stabil.

\section{PENUTUP}

\section{Kesimpulan}

Pada penelitian ini terlah berhasil dirancang perangkat telemonitoring EKG memiliki penguatan total 1397 kali, dengan bandwidth frekuensi rangkaian bandpass filter yang diloloskan sebesar 0.05-106 Hz. Jarak monitoring aplikasi EKG yang bisa diakses oleh server menggunakan bluetooth maksimum 5 meter tanpa halangan dan 3 meter dengan halangan. Aplikasi visualisasi sinyal EKG pada PC server, dapat menampilkan hasil rekaman EKG dengan baik dan perhitungan heart beat atau detak jantung sudah bisa ditampilkan pada aplikasi EKG pada PC server dengan rata-rata perbedaan antara aplikasi EKG dan detak jantung asli (denyut nadi) sebesar 2 beat dengan tingkat keakuratan sebesar $96.1 \%$. Dari keseluruhan hasil yang diperoleh, dapat disimpulkan bahwa alat yang dirancang telah memenuhi kriteria yang diharapkan dan dapat digunakan untuk aplikasi sistem monitoring detak jantung manusia pada dunia kedokteran.

\section{Saran}

Untuk pengembangan dan peningkatan lebih lanjut dari alat telemonitoring EKG ini ada beberapa poin yang perlu diperhatikan dalam perancangannya.

1. Untuk dapat memonitoring sinyal EKG yang lebih luas maka sebaiknya aplikasi EKG bisa di upload pada web hosting agar bias diakses oleh client dimanapun yang mendukung jaringan internet tanpa harus berada dalam jangkauan bluetooth.

2. Untuk hasil rekaman sinyal EKG yang dapat mendeteksi ma (Nastiti, A. K., Purwanti, E., \& Supardi, A., 2013)salah pada jantung seseorang sebaiknya pada aplikasi EKG tedapat indikator yang bisa mendeteksi masalah pada jantung yang telah dikonsultasikan pada dokter ahli jantung.

\section{Ucapan Terima Kasih}

Penulis menyampaikan terima kasih kepada pihak Fakultas Teknologi Industri, Universitas Trisakti dan Sekolah Tinggi Teknologi Indonesia yang telah mendukung penelitian ini.

\section{DAFTAR PUSTAKA}

Arduino, S. A. (2015). Arduino. Arduino LLC.

Datasheet amplifiers AD 620 series. (n.d.). Retrieved Februari 20, 2019, from Analog.com: http://www.analog.com/en/products/amplifiers/ ins trumentation-amplifiers/ad620.ht ml

Datasheet operational amplifier OPO series. (n.d.). Retrieved Februari 20, 2019, from all data sheet.com: www.alldatasheet.com/Datasheet+op07

Iskandar, I. A. (2015). PERANCANGAN ELEKTROKARDIOGRAF DENGAN TIGA ELEKTRODA MENGGUNAKAN FPGA SPARTAN-3. TRANSIENT, 4(3), 550-556.

Khan, M. D. (2016). Importance of High Order High Pas s and Low Pass Filter. World Applied Sciences Journal, 34(9), 1261-1268.

Mozaffarian, D., Benjamin, E. J., Go, A. S., Arnett, D. K., Blaha, M. J., Cushman, M., Howard, V. J. (2016). Heart disease and stroke statistics-2016 update a report from the American Heart Association. Circulation, 38-48.

Nastiti, A. K., Purwanti, E., \& Supardi, A. (2013). Klasifikasi Kelainan Jantung Dengan Metode Transformasi Fourier Dan Jaringan Saraf Tiruan.

Permana, D. (2015). DESAIN DAN IMPLEMENTASI PERANCANGAN ELEKTROKARDIOGRAF (EKG) BERBASIS BLUETOOTH. ALHAZEN Journal of Physics, 2(1). 